\title{
O financiamento do esporte no periodismo científico brasileiro: uma revisão sistemática
}

\section{RESUMO}

O presente estudo analisa a produção científica que versa sobre o financiamento do esporte brasileiro. Trata-se de uma revisão sistemática que avalia artigos científicos publicados entre os anos de 1998 a 2018 em periódicos nacionais relacionados à Educação Física/Ciências do Esporte, em língua portuguesa. Foram analisados, a partir da análise de conteúdo, 43 estudos que foram agrupados em quatro (04) categorias, a saber: i) gasto com a política esportiva ou o orçamento esportivo; ii) políticas ou programas esportivos específicos; iii) megaeventos esportivos; e iv) entidades de administração do esporte e prática esportiva. Os estudos se concentraram na análise da fonte orçamentária, da esfera federal e da categoria 'Políticas ou programas esportivos específicos'. Concluímos que o universo de 43 artigos sinaliza uma superação da incipiência sobre a temática, porém, com lacunas de estudos sobre as esferas subnacionais e privada, megaeventos e entidades de administração do esporte.

PALAVRAS-CHAVE: Financiamento; Política de esporte; Revisão sistemática

\begin{tabular}{|c|}
\hline $\begin{array}{r}\text { Claudia Catarino Pereira } \\
\text { Mestra em Educação Física } \\
\text { Instituto Federal do Sul de Minas Gerais } \\
\text {-IFSULDEMINAS, Pouso Alegre, Minas Gerais, } \\
\text { Brasil } \\
\text { claudiacatarino_@hotmail.com } \\
\text { @ https://orcid.org/0000-0001-8849-9472 }\end{array}$ \\
\hline $\begin{array}{r}\text { Fernando Henrique Silva Carneiro } \\
\text { Doutor em Educação Física } \\
\text { Instituto Federal de Goiás - IFG } \\
\text { Senador Canedo, Goiás, Brasil } \\
\text { fernandohenriquesc@gmail.com } \\
\text { [1 } \text { https://orcid.org/0000-0002-2800-1895 }\end{array}$ \\
\hline $\begin{array}{r}\text { Nadson Santana Reis } \\
\text { Mestre Educação Física } \\
\text { Universidade do Estado da Bahia - UNEB, } \\
\text { Departamento de Educação, Guanambi, Bahia, } \\
\text { Brasil } \\
\text { nadsonsr@hotmail.com } \\
\text { [1ttps://orcid.org/0000-0002-7796-2289 }\end{array}$ \\
\hline $\begin{array}{r}\text { Pedro Fernando Avalone Athayde } \\
\text { Doutor em Política Social } \\
\text { Universidade de Brasília - UnB, Faculdade de } \\
\text { Educação Física, Brasília, Distrito Federal, Brasil } \\
\text { pedroavalone@gmail.com } \\
\underline{\text { https://orcid.org/0000-0001-7219-3444 }}\end{array}$ \\
\hline $\begin{array}{r}\text { Fernando Mascarenhas } \\
\text { Doutor em Educação Física } \\
\text { Universidade de Brasília - UnB, Faculdade de } \\
\text { Educação Física, Brasília, Distrito Federal, Brasil } \\
\text { fernandom@unb.br } \\
{ }^{0} \text { http://orcid.org/0000-0003-0265-502X }\end{array}$ \\
\hline
\end{tabular}


The financing os sports in brazilian scientific journalism: a systematic review

\begin{abstract}
This study analyzes the scientific production that deals with the financing of Brazilian sport. This is a systematic review that evaluates scientific articles published between 1998 and 2018 in national journals related to Physical Education / Sport Sciences, in Portuguese. From the content analysis, 43 studies were analyzed, which were grouped into four (04) categories, namely: i) expenditure on sports policy or sports budget; ii) specific sports policies or programs; iii) mega sporting events; and iv) sports administration and sports practice entities. The studies focused on the analysis of the budget source, the federal sphere and the category 'Policies or specific sports programs'. We conclude that the universe of 43 articles signals an overcoming of the incipience on the theme, however, with gaps in studies on the subnational and private spheres, mega events and sports management entities.
\end{abstract}

KEYWORDS: Financing; Sports policy; Systematic review

\title{
EI financiamento del deporte em el periodismo científico brasileño: uma revisón sistemática
}

\section{RESUMEN}

El presente estudio analiza la producción científica que versa sobre el financiamiento del deporte brasileño. Se trata de una revisión sistemática que evalúa los artículos científicos publicados entre 1998 a 2018 revistas nacionales relacionados con la Educación Física / Ciencias del Deporte en portugués. Se analizaron, a partir del análisis de contenido, 43 estudios que se agruparon en cuatro (04) categorías, a saber: i) gastado con la política deportiva o el presupuesto deportivo; ii) políticas o programas deportivos específicos; iii) megaeventos deportivos; y iv) entidades de administración del deporte y práctica deportiva. Los estudios se concentraron en el análisis de la fuente presupuestaria, de la esfera federal y de la categoría 'Políticas o programas deportivos específicos'. El universo de 3 artículos señala uma superación de la incipiente sobre la temática, sin embargo, con lagunas de estudios sobre las esferas subnacionales y privadas, megaeventos y entidades de adminstración del deporte.

PALABRAS-CLAVE: Financiamiento; Política de deporte; Revisión sistemática 


\section{INTRODUÇÃO}

As políticas públicas possuem uma relação direta com a res publica, ou seja, com o que é de interesse de todos e configuram-se como um conjunto de ações que busca solucionar determinados problemas públicos (PEREIRA, 2009).

Para efetivação das políticas públicas (dentre elas a política esportiva) o fundo público é fundamental. As múltiplas funções do Estado são concretizadas a partir do fundo público que é formado pela punção compulsória realizada pelo mesmo Estado por meio de impostos, contribuições e taxas (BEHRING, 2010). Portanto, a presença de recursos públicos é necessária para que as políticas esportivas sejam materializadas.

O financiamento público do esporte foi reconhecido em lei - pela primeira vez - no Decreto-Lei $n^{\circ}$. 3.199/1941 ${ }^{1}$. Contudo, a maior parte da legislação esportiva sobre financiamento vigente no país foi produzida a partir de 1988 com a promulgação da Constituição Federal e a publicação da Lei nº 9.615/1998 (Lei Pelé)² (CARNEIRO, 2018).

Segundo Athayde (2015), o esporte nunca ocupou, no histórico da agenda governamental, um lugar de destaque ou de prioridade das ações públicas. Um importante marco para a mudança desse cenário foi o seu reconhecimento como direito na Constituição Federal de 1988 que, ao elevar o esporte à condição de direito e reponsabilidade do Estado, criou a obrigatoriedade para que esse direito fosse alvo de políticas públicas.

Partimos da compreensão de que analisar o financiamento da política esportiva é uma chave interpretativa importante para entender seus caminhos e prioridades, haja vista ser ele que possibilita sua materialidade (CARNEIRO; MASCARENHAS, 2018). As decisões tomadas em relação aos objetivos governamentais, as prioridades dos gastos estatais e a definição das fontes de recursos públicos representam não apenas elementos econômicos, quantitativos e técnicos, mas refletem principalmente correlações de força existentes de cunho político-social (SALVADOR, 2012).

Amaral, Ribeiro e Silva (2014) verificaram um crescimento da produção científicoacadêmica em políticas de esporte e lazer e, ao identificar lacunas ou incipiências, traçaram uma agenda de pesquisa sendo uma delas o financiamento do esporte (AMARAL; RIBEIRO; SILVA, 2014; ALMEIDA; MARCHI JÚNIOR, 2011; CARNEIRO; MASCARENHAS, 2018). Neste

\footnotetext{
${ }^{1}$ Decreto-lei baixado pelo então presidente Getúlio Vargas com o intuito de regulamentar as práticas físicas e esportivas no país, estabelecendo, para isso, as bases de organização dos desportos em todo o Brasil.

${ }^{2}$ Criada com o objetivo de dar mais transparência e profissionalismo ao esporte nacional, a referida lei instituiu o fim do passe nos clubes de futebol, o direito do consumidor nos esportes, disciplinou a prestação de contas por dirigentes de clubes e a criação de ligas, federações e associações de vários esportes. Além de determinar a profissionalização e transformação dos clubes em empresas, criando verbas para o esporte olímpico e paraolímpico dentre outras medidas.
} 
sentido, encontramos a proposta metodológica ${ }^{3}$ para análise do financiamento do esporte no Brasil de Carneiro e Mascarenhas (2018), que apresentaram a fonte, o direcionamento e a magnitude do gasto como indicadores importantes para se compreender a totalidade do financiamento da política esportiva.

A partir dos elementos supracitados surgiram questionamentos sobre a produção acadêmicocientífica na temática do financiamento do esporte: há incipiência de publicações? Quais são os temas privilegiados? O que expressam as publicações? Tendo por base estas questões, temos como objetivo analisar a produção acadêmico-científica sobre o financiamento do esporte no Brasil.

\section{DELINEAMENTO METODOLÓGICO}

Este estudo se caracteriza como uma revisão sistemática, ou seja, uma pesquisa que se utiliza de fonte de dados da literatura sobre determinado tema, buscando selecionar, organizar e analisar estudos, possibilitando compreender conceitos e comparar criticamente as análises (SAMPAIO; MANCINI, 2007).

Buscamos conhecer melhor o que vem sendo produzido e divulgado nos periódicos brasileiros vinculados à Educação Física/Ciência do Esporte no que tange ao financiamento do esporte. Definimos a opção por periódicos visto que são representativos da produção mais geral, pois a veiculação antecede ou sucede produções como livros, teses, dissertações e anais de eventos (BRACHT et al., 2011).

A partir da Plataforma Sucupira buscamos os periódicos vinculados a área de avaliação da Educação Física. Os critérios de seleção dos periódicos evolveram os seguintes aspectos: periódico cujo foco fosse a área de Educação Física/Ciência do Esporte e/ou Lazer; publicação brasileira e em português; na área de avaliação "Educação Física” ter Qualis-CAPES A2, B1 ou B2; e ter os artigos disponibilizados online entre 1998 e 2018. Esse período de análise se justifica por ser 1998 o ano da promulgação da Lei Pelé que estrutura o financiamento esportivo brasileiro e 2018 por ser o último ano completo para análise.

Assim, foram selecionados oito (08) periódicos, conforme quadro a seguir:

\footnotetext{
${ }^{3}$ Também encontramos os estudos de Starepravo, Souza e Marchi Júnior (2011) e Mezzadri, Silva e Figuerôa (2015) que propõe uma metodologia e um método, respectivamente, de análise das políticas públicas de esporte no Brasil. Porém, não orientam sua proposta apenas para a questão do financiamento, assim como Carneiro e Mascarenhas (2018).
} 
Quadro 1 - Revistas de divulgação Científica selecionadas

Revista de Educação Física da UFRGS (Movimento)

Revista do Programa de Pós-graduação Interdisciplinar em Estudos do Lazer (Licere)

Revista Brasileira de Ciências do Esporte (RBCE)

Revista Brasileira de Educação Física e Esporte (RBEFE)

Revista da Educação Física (REFUEM)

Revista de Educação Física, Esporte e Lazer (Motrivivência)

Revista Pensar a Prática (Pensar a Prática)

Revista Brasileira de Ciência e Movimento (RBC\&M)

Fonte: Elaboração própria.

Em cada revista buscamos produção científica sobre o tema em análise a partir dos descritores "fundo público", "financiamento", "orçamento" e "gasto esportivo". A inclusão dos artigos supunha trato, ao longo do texto, da discussão sobre financiamento e questões correlatas, ser artigo original e obedecer ao recorte temporal da análise.

A primeira etapa das buscas, desenvolvidas no portal de cada revista, envolveu análise a partir dos títulos, resumo e palavras-chave, resultando em cinquenta (50) artigos. Após leitura integral dos textos (segunda fase) foram selecionados quarenta e três (43) artigos. Os sete (07) textos excluídos não atendiam integralmente os critérios de inclusão supracitados.

Os trabalhos foram avaliados conforme as proposições de revisão sistemática de Sampaio e Mancine (2007), assim analisamos as temáticas abordadas pelos estudos compreendendo aquilo que foi privilegiado. Dessa forma, os artigos selecionados foram analisados a partir da análise de conteúdo que, segundo Bardin (2011), reúne procedimentos sistemáticos e objetivos de descrição do conteúdo das mensagens voltados à compreensão crítica do sentido das comunicações, seu conteúdo manifesto ou latente, as significações explícitas ou ocultas.

\section{APRESENTAÇÃO E DISCUSSÃO DOS DADOS}

Nessa direção, identificamos quatro (04) categorias, são elas: i) 'Gasto com a política esportiva ou o orçamento esportivo'; ii) 'Políticas ou programas esportivos específicos'; iii) 'Megaeventos esportivos'; e, iv) 'Entidades de administração do esporte e de prática esportiva'.

No gráfico 01 apresentamos a distribuição de artigos por categoria, onde percebemos uma concentração na categoria 'Políticas ou programas esportivos específicos', reunindo 49\% das publicações. Em seguida, analisaremos as categorias destacadas. 
Gráfico 1 - Concentração de artigos produzidos por categoria de análise.

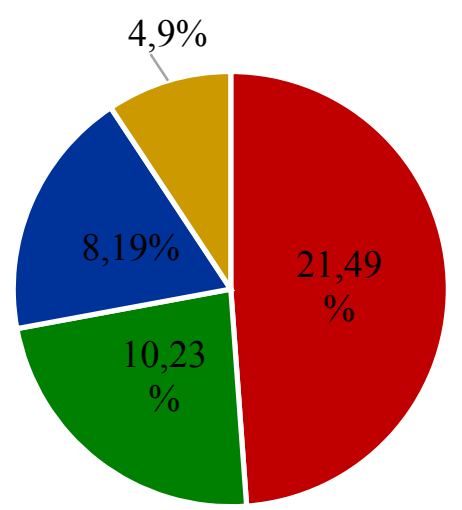

Políticas ou programas

esportivos específicos

Gasto com a política esportiva

ou o orçamento esportivo

- Megaeventos esportivos

Entidades de administração do

esporte e prática esportiva

Fonte: Elaboração própria.

\section{Políticas ou programas esportivos específicos}

Nesta categoria foram identificados vinte e um (21) artigos que pesquisaram programas, projetos e ações desenvolvidas pelos governos federal, estaduais e/ou municipais. Desses, dezessete (17) pesquisaram o âmbito federal, dois (02) o estadual, um (01) o municipal e um (01) o Distrito Federal. Assim, verificamos uma predominância de pesquisas que investigam a esfera federal.

Quadro 2 - Artigos científicos que pesquisaram o financiamento de políticas públicas e/ou programas esportivos.

\begin{tabular}{|c|c|c|c|}
\hline Periódico & Ano & Artigo & Autores \\
\hline RBCE & 2010 & $\begin{array}{l}\text { Esporte universitário brasileiro: uma leitura } \\
\text { a partir e suas relações com o Estado }\end{array}$ & $\begin{array}{l}\text { STAREPRAVO, } \\
\text { F. et al. }\end{array}$ \\
\hline Licere & 2013 & $\begin{array}{l}\text { A política esportiva do governo Lula: o } \\
\text { programa Segundo Tempo }\end{array}$ & MATIAS, W. \\
\hline Licere & 2013 & $\begin{array}{l}\text { Do direito ao lazer: o princípio acesso no } \\
\text { Programa Esporte na Comunidade } \\
\text { (Fortaleza-CE) }\end{array}$ & $\begin{array}{l}\text { OLIVEIRA, A.; } \\
\text { SUASSUNA, D.; } \\
\text { TROMPIERI FILHO, } \\
\text { N. }\end{array}$ \\
\hline $\begin{array}{l}\text { Pensar a } \\
\text { Prática }\end{array}$ & 2014 & $\begin{array}{l}\text { Financiamento do esporte olímpico de } \\
\text { verão brasileiro: mapeamento inicial do } \\
\text { programa "bolsa-atleta" }\end{array}$ & $\begin{array}{l}\text { CORRÊA, A,; } \\
\text { et al. }\end{array}$ \\
\hline Movimento & 2015 & $\begin{array}{l}\text { A Lei de Incentivo Fiscal e o (não) direito } \\
\text { ao esporte }\end{array}$ & $\begin{array}{l}\text { MATIAS, W. et } \\
\text { al. }\end{array}$ \\
\hline $\begin{array}{l}\text { Motrivivênci } \\
\text { a }\end{array}$ & 2016 & $\begin{array}{l}\text { Possíveis relações entre investimentos } \\
\text { públicos e obtenção de resultados: o caso } \\
\text { da natação brasileira }\end{array}$ & $\begin{array}{l}\text { ORDONHES, } \\
\text { M.; LUZ, W.; } \\
\text { CAVICHIOLLI, F. }\end{array}$ \\
\hline $\begin{array}{l}\text { Motrivivênci } \\
\text { a }\end{array}$ & 2016 & $\begin{array}{l}\text { O panorama do judô no programa 'bolsa- } \\
\text { atleta": uma análise entre os anos } 2011 \text { a } \\
2013\end{array}$ & DIAS, Y.; et al. \\
\hline $\begin{array}{l}\text { Motrivivênci } \\
\text { a }\end{array}$ & 2016 & $\begin{array}{l}\text { O financiamento do esporte em Santa } \\
\text { Catarina: o caso do Fundesporte nos anos } \\
\text { de } 2011 \text { e } 2012\end{array}$ & $\begin{array}{l}\text { FURTADO, S. } \\
\text { et al. }\end{array}$ \\
\hline $\begin{array}{l}\text { Pensar a } \\
\text { Prática }\end{array}$ & 2016 & $\begin{array}{l}\text { O judô no programa governamental bolsa- } \\
\text { atleta: a distribuição espacial dos bolsistas }\end{array}$ & DIAS, Y.; et al. \\
\hline
\end{tabular}




\begin{tabular}{|c|c|c|c|}
\hline & & $(2011-2013)$ & \\
\hline RBC\&M & 2016 & $\begin{array}{l}\text { O financiamento do esporte de alto } \\
\text { rendimento no Brasil: uma análise do } \\
\text { programa "Brasil no Esporte de Alto } \\
\text { Rendimento" }(2004-2011)\end{array}$ & $\begin{array}{l}\text { CASTRO, S.; } \\
\text { POFFO, B.; SOUZA, } \\
\text { D. }\end{array}$ \\
\hline $\mathrm{RBCE}$ & 2017 & 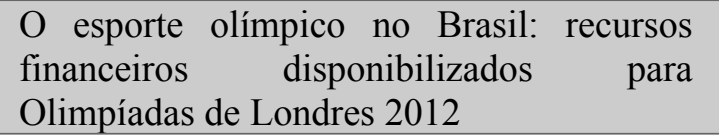 & $\begin{array}{l}\text { TEIXEIRA, M.; } \\
\text { MATIAS, W.; } \\
\text { MASCARENHAS, F. }\end{array}$ \\
\hline Licere & 2017 & $\begin{array}{l}\text { O Programa Esporte e Lazer da Cidade nos } \\
\text { planos plurianuais do governo federal: o } \\
\text { "estresse esportivo" do PELC }\end{array}$ & SOARES, J. \\
\hline Licere & 2017 & Municiplização do esporte e do lazer & $\begin{array}{l}\text { PINTOS, A.; } \\
\text { ATHAYDE, P.; } \\
\text { GODOFLITE, } \mathrm{M} \text {. }\end{array}$ \\
\hline $\begin{array}{l}\text { Motrivivênci } \\
\text { a }\end{array}$ & 2017 & $\begin{array}{l}\text { A agenda do futebol no governo Lula: } \\
\text { ações rumo à Copa do Mundo FIFA } 2014\end{array}$ & $\begin{array}{l}\text { RIBEIRO, M.; } \\
\text { et al. }\end{array}$ \\
\hline $\begin{array}{l}\text { Motrivivênci } \\
\text { a }\end{array}$ & 2017 & $\begin{array}{l}\text { Financiamento público e esporte } \\
\text { educacional: uma análise do processo } \\
\text { orçamentário do programa "Segundo } \\
\text { Tempo" (2004-2011) }\end{array}$ & $\begin{array}{l}\text { CASTRO, S.; } \\
\text { SCARPIN, J.; SOUZA, } \\
\text { D. }\end{array}$ \\
\hline $\begin{array}{l}\text { Motrivivênci } \\
\text { a }\end{array}$ & 2017 & $\begin{array}{l}\text { O programa bolsa atleta no contexto } \\
\text { esportivo nacional }\end{array}$ & $\begin{array}{l}\text { TEIXEIRA, M.; } \\
\text { et al. }\end{array}$ \\
\hline Licere & 2018 & $\begin{array}{l}\text { Os centros olímpicos do Distrito Federal: } \\
\text { um caso de desresponsabilização do Estado } \\
\text { e descentralização das políticas de esporte e } \\
\text { lazer em direção ao "terceiro setor" }\end{array}$ & $\begin{array}{l}\text { CARNEIRO, F. } \\
\text { et al. }\end{array}$ \\
\hline Movimento & 2018 & $\begin{array}{l}\text { Análise da capacidade fiscal per capita na } \\
\text { descentralização do programa Segundo } \\
\text { Tempo/ME junto aos municípios }\end{array}$ & $\begin{array}{l}\text { SANTOS, E.; } \\
\text { STAREPRAVO, F. }\end{array}$ \\
\hline $\begin{array}{l}\text { Motrivivênci } \\
\text { a }\end{array}$ & 2018 & $\begin{array}{l}\text { A organização e configuração do esporte } \\
\text { universitário no Brasil (1940-1980) }\end{array}$ & $\begin{array}{l}\text { CARMARGO, } \\
\text { P.; MEZZADRI, F. }\end{array}$ \\
\hline $\begin{array}{l}\text { Pensar a } \\
\text { Prática }\end{array}$ & 2018 & $\begin{array}{l}\text { Financiamento público no esporte: } \\
\text { os repasses do estado de Santa Catarina } \\
\text { para projetos da mesorregião grande } \\
\text { Florianópolis (2007-2014) }\end{array}$ & $\begin{array}{l}\text { QUINAUD, R.; } \\
\text { ALMEIDA, B. }\end{array}$ \\
\hline
\end{tabular}

Fonte: Periódicos analisados. (Elaboração própria)

Pela especificidade de tais pesquisas, que analisaram políticas ou programas específicos, a fonte de dados e os documentos utilizados foram diversos. O Portal da Transparência do Governo Federal $^{4}$ foi a fonte de dados mais utilizada, sendo o SIGA Brasil ${ }^{5}$ utilizado em apenas três (03) pesquisas. Surge nesta categoria a análise de Planos Plurianuais (PPAs) e das Leis de Diretrizes Orçamentárias (LOAs).

O programa mais pesquisado na esfera federal foi o Bolsa Atleta ${ }^{6}$, analisado em quatro (04)

\footnotetext{
${ }^{4}$ O Portal da Transparência do Governo Federal é um site no qual qualquer cidadão pode encontrar informações sobre a utilização do dinheiro público e sobre assuntos relacionados à gestão pública. Disponível em: http://www.portaltransparencia.gov.br/.

${ }^{5}$ O SIGA Brasil é um sistema de informações sobre o orçamento público federal que permite acesso amplo e facilitado aos dados do Sistema Integrado de Administração Financeira-SIAFI e a outras bases de dados sobre planos e orçamentos públicos. Disponível em: https://www12.senado.leg.br/orcamento/sigabrasil.
} 
artigos. Encontramos conclusões similares nos estudos de Teixeira et al (2017), Dias et al (2016 ${ }^{\mathrm{a}}$ e Corrêa et al (2014), quais sejam: concentração de recursos destinados às bolsas de nível intermediário na pirâmide esportiva (bolsas nacionais e internacionais), voltadas a atletas prontos, fomentando uma pirâmide esportiva com a base e o topo enfraquecidos.

Teixeira et al (2016) verificou que 50\% dos atletas classificados para os jogos olímpicos de Pequim (2008), Londres (2012) e Rio (2016) eram bolsistas e, desses, apenas 0,11\% foram medalhistas, muito embora, nos jogos do Rio (2016), todos os atletas medalhistas eram bolsistas. Dias et al (2016b) verificaram, a partir do estudo sobre o judô, que a região sudeste concentrou $51,46 \%$ das bolsas, dado similar ao que Corrêa et al (2014) verificaram em sua pesquisa em âmbito federal.

Condizente com a análise sobre a baixa efetividade do Bolsa Atleta, Teixeira, Matias e Mascarenhas (2017) pesquisaram o esporte olímpico brasileiro de 2009 a 2012 e verificaram que o montante de R\$1,4 bilhão ${ }^{7}$ destinado ao Comitê Olímpico Brasileiro (COB) e às confederações de esportes olímpicos não gerou resultados expressivos no quadro de medalhas.

Ordonhes, Luz e Cavichiolli (2016) cruzaram os dados do Programa Bolsa Atleta e da Lei de Incentivo ao Esporte (LIE) referentes à natação (alto rendimento) e concluíram que podem existir relações entre atletas contemplados no Programa Bolsa Atleta e os resultados obtidos, porém tal possiblidade não foi vislumbrada a partir da LIE. Novamente surgem elementos que mostram a concentração de recursos, assim como analisado no esporte olímpico: as instituições esportivas com maior número de atletas de destaque foram as que tiveram maior número de bolsas concedidas e as três instituições esportivas ${ }^{8}$ com maior número de ocorrência no ranking nacional foram as que receberam maior número de bolsas.

Castro, Poffo e Souza (2016) analisaram as dotações orçamentárias do programa "Brasil no Esporte de Alto Rendimento"9 de 2004 a 2011 e verificaram um crescimento no volume de recursos liquidados para o esporte de alto rendimento, porém 48,4\% das dotações autorizadas não foram executadas, o que revela descontinuidades e baixos investimentos no programa.

O Programa Esporte e Lazer da Cidade (PELC) ${ }^{10}$ foi analisado em três (03) artigos. Castro,

\footnotetext{
${ }^{6}$ Bolsa Atleta é um programa criado em 2005 e que visa ampliar o financiamento direto dos atletas, fomentando bolsas em seis níveis: Atleta de Base, Estudantil, Nacional, Internacional, Olímpico e Pódio.

${ }^{7}$ Tais recursos foram destinados a partir da Lei Agnelo/Piva, de convênios com o ME, de patrocínio das empresas estatais e de recursos da LIE, entre os anos de 2009 e 2012 (TEIXEIRA; MATIAS; MASCAREHAS, 2017).

${ }^{8}$ Minas Tênis Clube, Esporte Clube Pinheiros e Corinthians.

"O programa "Brasil no Esporte de Alto Rendimento" foi apresentado no PPA 2004-2007, com objetivo em aprimorar o desempenho de atletas brasileiros e promover a imagem do país no exterior. A partir do PPA 2008-2011, o programa passou a se denominar "Brasil no Esporte de Alto Rendimento - Brasil Campeão".

${ }^{10}$ O PELC foi criado em 2003 pelo ME, e se desenvolve baseado na implantação de núcleos do programa a partir de convênios e termos e execução descentralizada firmados entre o Me e Municípios, Governos de Estado, Distrito
} 
Starepravo e Souza (2018) investigaram a composição orçamentária do PELC de 2004 a 2011 e que 96,3\% dos valores sancionados para o programa na LOA foram a partir de acréscimos propostos por emendas parlamentares. Tais autores, assim como Soares (2017), verificaram uma baixa execução orçamentária e a prioridade do gasto com infraestrutura esportiva, o que desconsidera as diretrizes e princípios do programa. Pintos, Athayde e Godoflite (2017) pesquisaram a municipalização do PELC e sinalizaram a importância do financiamento para sua efetivação.

Analisando o Programa Segundo Tempo (PST) ${ }^{11}$, Santos e Starepravo (2018 ${ }^{\mathrm{a}}$ ) verificaram um baixo número de convênios das prefeituras com o Ministério do Esporte (ME) para execução do programa. Matias (2013) e Castro, Scarpin e Souza (2017) afirmaram que o PST não foi prioridade de gasto do $\mathrm{ME}$, sendo afetado diretamente pela mudança de rumo das políticas de esporte com a chegada dos Jogos Panamericano Rio 2007.

A análise do financiamento do esporte via LIE foi realizado por Matias et al (2015) que constataram uma hegemonia do esporte de alto rendimento nas propostas contempladas entre 2007 e 2013 e uma rasa contribuição para a democratização do acesso ao esporte. E, de modo complementar, Ribeiro et al (2017) analisaram a agenda governamental voltada ao futebol durante o governo Lula e constataram que foi a modalidade mais beneficiada pela LIE.

Starepravo et al (2010) e Camargo e Mezzadri (2018) pesquisaram o esporte universitário e apresentaram uma relação de interdependência, principalmente no âmbito econômico, entre Estado e o esporte universitário por meio do financiamento público.

No âmbito estadual, encontramos duas pesquisas sobre o Fundo Estadual de Incentivo ao Esporte de Santa Catarina (FUNDESPORTE). Furtado et al (2016) mapearam a alocação de recursos do FUNDESPORTE (2011 e 2012) e Quinaud e Almeida (2018) analisaram as propostas contempladas na mesorregião de Grande Florianópolis (2007 e 2014). Com conclusões complementares, os autores verificaram que a maioria dos recursos foi destinada a proponentes de ordem jurídica e com prioridade de gasto para infraestrutura esportiva, eventos e atletas e equipes de alto rendimento.

$\mathrm{Na}$ esfera distrital, Carneiro et al (2018) pesquisaram o programa Centros Olímpicos do Distrito Federal $(\mathrm{Cos})^{12}$ buscando compreender, dentre outros aspectos, a configuração e

Federal, Universidades Estaduais, Universidades Públicas Federais ou Institutos Federais de Educação. Possui diversos objetivos, sendo um deles democratizar o acesso ao lazer e ao esporte recreativo, privilegiando as comunidades menos favorecidas.

${ }^{11}$ O PST também criado em 2003 visa democratizar o acesso ao esporte e à cultura do esporte educacional. Possui como público alvo crianças e adolescentes. O programa é desenvolvido através da formalização de parcerias entre o ME e entidades públicas, com vigência pré-estabelecida de 24 meses.

${ }^{12}$ Os COs têm por finalidade assegurar atendimento socioeducativo por meio das práticas esportivas, oferecendo prioritariamente a crianças e a adolescentes uma vivência baseada em valores como cooperação, solidariedade, 
abrangência do gasto entre 2008 e 2015. Os autores verificaram que o programa foi a prioridade da política esportiva do Distrito Federal, porém apresentou uma baixa execução orçamentária onde apenas metade dos recursos previstos foram liquidados.

No âmbito municipal, Oliveira, Suassuna e Trompieri Filho (2013) analisaram o Programa Esporte na Comunidade (PEC) ${ }^{13}$ no município de Fortaleza/CE e verificaram uma escassez de recursos orçamentários, o que impactou diretamente a qualidade dos serviços prestados à comunidade e a materialização do lazer como direito social.

Nesta categoria, verificamos que a prioridade recaiu sobre o período dos governos Lula e Dilma, com concentração entre os anos 2007 e 2012, e sobre a esfera federal. É importante destacar que tal cenário responde à intensificação da produção, implementação das políticas de esporte e lazer a partir da criação do ME e realização dos megaeventos esportivos. Apesar de maior diversidade de objetos de pesquisa, enxergamos considerações convergentes: recursos escassos, baixa execução orçamentária, má distribuição de recursos, baixa efetividade dos investimentos e prioridade do gasto com infraestrutura.

\section{Gasto com a política esportiva ou orçamento esportivo}

Esta categoria reúne os artigos que analisaram os gastos orçamentários ou os gastos com as políticas em âmbito federal, estadual e municipal. Dos dez (10) artigos pertencentes a essa categoria, cinco (05) deles pesquisaram o âmbito federal, dois (02) pesquisaram o Distrito Federal e três (03) o âmbito municipal.

Quadro 3 - Artigos científicos que pesquisaram o gasto e/ou orçamento em âmbito federal, estadual e municipal.

\begin{tabular}{lclc}
\hline Periódico & Ano & \multicolumn{1}{c}{ Artigo } & Autores \\
\hline Movimento & 2010 & $\begin{array}{l}\text { O financiamento dos programas federais de } \\
\text { esporte e lazer no Brasil (2004 a 2008) }\end{array}$ & $\begin{array}{c}\text { ALMEIDA, B.; } \\
\text { MARCHI JÚNIOR, V. }\end{array}$ \\
\hline Licere & $2014 \begin{array}{l}\text { O direito ao esporte: análise do planejamento e } \\
\text { execução de políticas públicas no Distrito Federal } \\
\text { no período de 2008-2011 }\end{array}$ & $\begin{array}{c}\text { CARNEIRO, F.; } \\
\text { MASCARENHAS, F. }\end{array}$ \\
\hline RBEFE & $2015 \begin{array}{l}\text { Gestão das políticas públicas do Ministério do } \\
\text { Esporte do Brasil }\end{array}$ & $\begin{array}{c}\text { SILVA, D.; } \\
\text { BORGES, C.; AMARAL, } \\
\text { S. }\end{array}$ \\
\hline RBCE & 2015 & $\begin{array}{l}\text { Primeiras aproximações de uma análise do } \\
\text { financiamento da política de esporte e lazer no } \\
\text { Governo Lula }\end{array}$ & $\begin{array}{c}\text { ATHAYDE, P.; } \\
\text { MASCARENHAS, F.; } \\
\text { SALVADOR, E. }\end{array}$ \\
\hline
\end{tabular}

pensamento crítico, dentre outros. É desenvolvido pela Secretaria do Esporte, Turismo e Lazer sob forma de convênios com entidades sem fins lucrativos.

${ }^{13}$ O programa, desenvolvido pela Prefeitura Municipal de Fortaleza, busca implantar núcleos do programa com objetivo em democratizar o acesso ao esporte e ao lazer através de intervenções nas comunidades. 


\begin{tabular}{lclc}
\hline RBEFE & 2016 & $\begin{array}{l}\text { O orçamento do esporte: aspectos da atuação } \\
\text { estatal de FHC a Dilma }\end{array}$ & $\begin{array}{c}\text { MASCARENHAS, } \\
\text { F. }\end{array}$ \\
\hline RBC\&M & 2017 & $\begin{array}{l}\text { Financiamento e políticas públicas de esporte e } \\
\text { lazer: uma análise da gestão no município de } \\
\text { Santarém/PA (2005-2012) }\end{array}$ & $\begin{array}{c}\text { GRASSO, R.; } \\
\text { ISAYAMA, H. }\end{array}$ \\
\hline RBC\&M & 2018 & $\begin{array}{l}\text { Políticas de esporte do Distrito Federal: uma } \\
\text { análise sobre a legislação, gestão e o } \\
\text { financiamento entre os anos de 2008 a 2014 }\end{array}$ & $\begin{array}{c}\text { ATHAYDE, P.; } \\
\text { DALMAS, L. }\end{array}$ \\
\hline Movimento & 2018 & $\begin{array}{l}\text { Esporte, fundo público e pequena política: os } \\
\text { reveses de um orçamento (r)emendado }\end{array}$ & $\begin{array}{c}\text { TEIXEIRA, M. et } \\
\text { al }\end{array}$ \\
\hline Licere & 2018 & $\begin{array}{l}\text { Estrutura político-administrativa dos governos } \\
\text { municipais do Piauí e investimento no esporte e } \\
\text { no lazer }\end{array}$ & $\begin{array}{r}\text { SANTOS, E.; } \\
\text { STAREPRAVO, F. }\end{array}$ \\
\hline Motrivivência & 2018 & $\begin{array}{l}\text { Evolução das despesas da função desporto e lazer } \\
\text { (FDL) dos municípios do estado do Piauí de 2003 } \\
\text { a 2011 }\end{array}$ & $\begin{array}{r}\text { SANTOS, E.; } \\
\text { STAREPRAVO, F.; } \\
\text { CANAN, F. }\end{array}$ \\
\hline
\end{tabular}

Fonte: Periódicos analisados. (Elaboração própria).

De forma predominante, o portal SIGA Brasil foi adotado em cinco (05) das pesquisas da esfera federal, sendo o principal meio utilizado para acesso aos dados.

Os estudos realizaram análises quantitativas e qualitativas do financiamento esportivo, apesar de apenas seis dos artigos sinalizarem tal opção de análise. Destacamos tais escolhas metodológicas pois o orçamento não é uma peça meramente econômica, mas eminentemente política. Salvador (2012) afirma que o orçamento é a expressão mais visível do fundo público e, por consequência, demonstra as prioridades das políticas públicas definidas pelos governos. E, não menos importante, expressa as correlações de força existentes entre o Estado, a sociedade civil e as frações de classe (componentes do bloco no poder). Assim, uma análise meramente técnica ou quantitativa dos dados impossibilitaria perceber reais interesses e relações que giram em torno das políticas de esporte.

Identificamos quatro pesquisas com objetivos próximos e que tematizaram o gasto federal de forma mais ampla. Mascarenhas (2016) e Almeida e Marchi Júnior (2010) orientaram suas pesquisas para os gastos federais de 2001 a 2012 e de 2004 a 2008, respectivamente. Já Silva, Borges e Amaral (2015) e Athayde, Mascarenhas e Salvador (2015) investigam as ações do ME de 2002 a 2012 e de 2003 a 2010, respectivamente.

Tais estudos verificaram oscilações de prioridade dos gastos, sendo as práticas esportivas foco do governo do Fernando Henrique Cardoso (FHC) e dos governos Lula e Dilma a infraestrutura esportiva e os megaeventos, onde em anos específicos foi priorizado o atendimento da área social (esporte nas dimensões educacional e de participação).

Teixeira et al (2018) analisaram o gasto orçamentário a partir das emendas parlamentares e verificaram uma representatividade média de $72 \%$ na execução orçamentária do ME, com 
direcionamento prioritário para infraestrutura no período de 2008 a 2011, e para ações de esporte, lazer e inclusão social no período de 2012 a 2015. Esta alta representatividade na execução orçamentária demonstra, segundo os autores, as problemáticas práticas clientelistas no setor esportivo pertinente ao governo federal.

Já no Distrito Federal, Carneiro e Mascarenhas (2014) e Athayde e Dalmas (2018) pesquisaram, respectivamente, a política de esporte do Governo do Distrito Federal (GDF) de 2008 a 2011 e o orçamento da Secretaria de Estado de Esporte, Turismo e Lazer do Distrito Federal (SETL-DF) de 2008 a 2014. Os autores sinalizaram limites da previsão de gastos na lei e nos valores efetivamente gastos (liquidados), prioridade do gasto para as atividades de gestão e atividades meio da secretaria, e descontinuidades principalmente na quebra dos investimentos nas ações de prática e vivência esportiva.

No âmbito municipal, Santos, Starepravo e Canan (2018) e Santos e Starepravo (2018b) analisaram os investimentos em esporte e lazer nos municípios do estado do Piauí, verificando um crescimento exponencial dos investimentos dos municípios em políticas públicas de esporte e lazer, contrapondo os argumentos de que os municípios não contribuem para o desenvolvimento do esporte e do lazer no país.

O município de Santarém/PA foi pesquisado por Grasso e Isayama (2017) que reconheceram que o financiamento das políticas de esporte e lazer do município foi expressivo e que, apesar das oscilações, houve uma ampliação desse financiamento, com priorização do esporte comunitário e educacional.

Nesta categoria, a prioridade foi para pesquisas na esfera federal e no período dos governos Lula e Dilma. Apesar dos diferentes objetos analisados, despontaram conclusões que verificaram baixas execuções e descontinuidades no gasto orçamentário.

\section{Megaeventos Esportivos}

Esta categoria reúne artigos que pesquisaram os megaeventos esportivos realizados no Brasil: Jogos Pan-Americanos Rio 2007, Jogos Mundiais Militares 2011, Copa do Mundo FIFA 2014 e Jogos Olímpicos Rio 2016. Foram oito (08) artigos que tematizaram o financiamento de tais eventos, publicados de 2009 em diante. A princípio, é um número baixo de publicações considerando a expressão e quantidade de eventos realizados de 2007 a 2016.

Quadro 4 - Artigos científicos que pesquisaram o financiamento de megaeventos esportivos.

$\begin{array}{llll}\text { Periódico Ano } & \text { Artigo } & \text { Autores }\end{array}$




\begin{tabular}{|c|c|c|c|}
\hline $\begin{array}{l}\text { Motrivivênci } \\
\text { a }\end{array}$ & 2009 & $\begin{array}{l}\text { Observações sobre os impactos esperados dos } \\
\text { Jogos Olímpicos de } 2016\end{array}$ & PRONI, M. \\
\hline $\begin{array}{l}\text { Motrivivênci } \\
\text { a }\end{array}$ & 2013 & $\begin{array}{l}\text { A cidadania ferida no país da copa: as obras } \\
\text { públicas para os megaeventos sob o sorriso do } \\
\text { lagarto }\end{array}$ & $\begin{array}{l}\text { SOARES, M.; } \\
\text { BEHMOIRAS, D.; } \\
\text { SAMPAIO, J. }\end{array}$ \\
\hline $\begin{array}{l}\text { Motrivivênci } \\
\text { a }\end{array}$ & 2013 & $\begin{array}{l}\text { Rio 2016: possibilidades e desafios para o } \\
\text { esporte brasileiro }\end{array}$ & $\begin{array}{l}\text { FIGUERÔA, } \\
\text { K.; MEZZADRI, F.; } \\
\text { SILVA, M.; SILVA, } \\
\text { M. }\end{array}$ \\
\hline $\begin{array}{l}\text { Motrivivênci } \\
\text { a }\end{array}$ & 2014 & $\begin{array}{l}\text { Planejamento, ações e financiamento para o } \\
\text { esporte em tempos de megaeventos }\end{array}$ & $\begin{array}{l}\text { FIGUERÔA, } \\
\text { K. et al. }\end{array}$ \\
\hline Licere & 2014 & Rio 2016 e os legados do esporte de lazer & $\begin{array}{l}\text { FIGUERÔA, } \\
\text { K.; MEZZADRI, F.; } \\
\text { SILVA, M. }\end{array}$ \\
\hline RBEFE & 2015 & $\begin{array}{l}\text { Os jogos olímpicos e paraolímpicos Rio 2016: } \\
\text { propostas para o esporte educacional, de } \\
\text { participação e de rendimento }\end{array}$ & $\begin{array}{l}\text { CASTRO, S.; } \\
\text { SOUZA, D. }\end{array}$ \\
\hline RBEFE & 2015 & $\begin{array}{l}\text { Legados de megaeventos esportivos: } \\
\text { considerações a partir de uma perspectiva } \\
\text { crítica }\end{array}$ & $\begin{array}{l}\text { COAKLEY, } \\
\text { J.; SOUZA, D. }\end{array}$ \\
\hline $\begin{array}{l}\text { Pensar a } \\
\text { prática }\end{array}$ & 2017 & $\begin{array}{l}\text { As influências dos megaeventos esportivos na } \\
\text { agenda e políticas esportivas: planejamento } \\
\text { institucional, ordenamento jurídico e } \\
\text { financeiro }\end{array}$ & $\begin{array}{l}\text { MATIAS, W.; } \\
\text { MASCARENHAS, F. }\end{array}$ \\
\hline
\end{tabular}

Fonte: Periódicos analisados. (Elaboração própria)

Cinco (05) $\operatorname{artigos}^{14}$ pesquisaram os Jogos Olímpicos Rio 2016: Figuerôa, Mezzadri e Silva (2014), Figuerôa, Mezzadri e Silva (2013), Figuerôa et al (2014), Castro e Souza (2015) e Proni (2009). Destes, quatro (04) se aproximaram por utilizarem dois documentos centrais na análise dos dados: o Dossiê de Candidatura e os Cadernos de Legados dos Jogos Olímpicos e Paralímpicos Rio 2016.

Castro e Souza (2015) utilizaram apenas os dois documentos supracitados. Figuerôa, Mezzadri e Silva (2013) utilizaram, além dos dois documentos citados, o Plano Decenal de Esporte e Lazer (PDEL). Figuerôa et al (2014) e Figuerôa, Mezzadri e Silva (2014) utilizaram, além dos três documentos anteriores, os sites oficiais do governo para acesso a documentos oficiais de prestação de contas do Governo Federal, os PPAs, e realizaram entrevistas com agentes da Autoridade Pública Olímpica (APO) e do ME.

Figuerôa et al (2014) e Figuerôa, Mezzadri e Silva (2014) apresentaram as previsões de investimento presentes nos documentos analisados e verificaram uma grande queda nos valores liquidados para o desporto comunitário e concomitante aumento do gasto com esporte de alto rendimento e infraestrutura esportiva.

\footnotetext{
${ }^{14}$ Tais artigos não analisaram os Jogos Olímpicos Rio 2016 durante ou após sua execução, mas sim em anos anteriores e se balizando nos valores de investimento estimados nos documentos oficiais.
} 
Castro e Souza (2015), noutra direção, argumentaram que os documentos não satisfazem os preceitos da Constituição Federal em relação ao esporte e nem da Política Nacional de Esporte. Há uma concentração de ações na cidade do Rio de Janeiro, falta de incentivo ao esporte educacional via educação física escolar, bem como lacunas sobre planejamento orçamentário. Os autores verificaram, assim como Figuerôa, Mezzadri e Silva (2013), que há uma falta de consistência e detalhamento das propostas, e que, conquanto sinalizem legados para os Jogos Olímpicos Rio 2016, não há ações planejadas nem caminhos apresentados para execução.

Proni (2009) apresentou os valores previstos para os Jogos Olímpicos Rio 2016 e destacou a existência de possíveis impactos positivos com a realização dos jogos. Contudo, sinalizou que tais legados poderiam não ser alcançados assim como em Atenas (2004).

Com um olhar mais amplo, Matias e Mascarenhas (2017) e Coackley e Souza (2015) analisaram os megaeventos esportivos a partir dos determinantes econômicos e políticos. Os últimos utilizaram os jogos Pan Rio 2007 como exemplo de um evento com o custo muito elevado, acima dos valores previstos em planejamento, e que no período pós-evento o acesso aos equipamentos construídos se demonstrou insuficiente e ineficaz para a democratização da prática esportiva como direito. Partindo do pressuposto de que megaeventos esportivos promovem desenvolvimento econômico, social e político, os autores afirmaram que apenas setores específicos seriam beneficiados e que a população, de forma geral, não seria diretamente favorecida.

E, por último, Soares, Behmoiras e Sampaio (2013), sendo os únicos que discutiram a Copa do Mundo FIFA 2014. Os autores apresentaram diversos argumentos de que a Copa e os demais megaeventos esportivos foram "a concretização dos caprichos das elites" brasileiras, estando longe de alcançar a legitimamente do esporte mais praticado no Brasil.

Percebemos que a produção de artigos sobre os megaeventos esportivos se concentra na apreciação dos Jogos Olímpicos Rio 2016 e na análise dos documentos de candidatura e de propostas de legados. Verificamos uma lacuna na produção de estudos que pesquisem a materialidade dos legados.

\section{Entidades de Administração do Esporte e de Prática Esportiva}

Nesta categoria reunimos os quatro (04) artigos que tinham como objeto de pesquisa examinar o financiamento das entidades de administração do esporte e de prática esportiva ${ }^{15}$. Esta categoria é a que possui menor número de artigos.

\footnotetext{
${ }^{15}$ Partimos das definições de entidades de administração do esporte e entidades de prática esportivas constantes na Lei Pelé.
} 
Quadro 4 - Artigos científicos sobre o financiamento das Entidades de Administração do Esporte e de Prática Esportiva.

\begin{tabular}{lclc}
\hline Periódico & Ano & \multicolumn{1}{c}{ Artigo } & Autores \\
\hline $\begin{array}{l}\text { Pensar a } \\
\text { Prática }\end{array}$ & 2012 & $\begin{array}{l}\text { A relação Governo Federal e Comitê Olímpico } \\
\text { Brasileiro com base na análise da lei } \\
10.264 / 2001 \text { (Agnelo-Piva) no período de 2005 } \\
\text { a 2008 }\end{array}$ & $\begin{array}{c}\text { ALMEIDA, } \\
\text { B.; MARCHI } \\
\text { JÚNIOR, V. }\end{array}$ \\
\hline $\begin{array}{l}\text { REFUE } \\
\text { M financiamento público do rugby brasileiro: a } \\
\text { relação Governo Federal e Confederação } \\
\text { Brasileira de Rugby (CBRu) }\end{array}$ & $\begin{array}{c}\text { SILVA, M. et } \\
\text { al }\end{array}$ \\
\hline RBCE & 2015 & $\begin{array}{l}\text { Comitê Olímpico Brasileiro e o financiamento } \\
\text { das confederações brasileiras }\end{array}$ & $\begin{array}{c}\text { ALMEIDA, } \\
\text { BARCHI JÚNIOR, } \\
\text { W. }\end{array}$ \\
\hline RBEFE & 2011 & $\begin{array}{l}\text { Gestão do voleibol no Brasil: o caso das equipes } \\
\text { participantes da Superliga 2007-2008 }\end{array}$ & $\begin{array}{l}\text { MENDES, D.; } \\
\text { BASTOS, F. }\end{array}$ \\
\hline
\end{tabular}

Fonte: Periódicos analisados. (Elaboração própria)

Almeida e Marchi Júnior (2011), ao se propor identificar o relacionamento estabelecido entre as confederações de esportes olímpicos e o COB, verificaram uma centralização das decisões na entidade que, por sua vez, reflete na distribuição de verbas entre as confederações. Os repasses financeiros feitos às confederações via $\mathrm{COB}$ são questionáveis, principalmente pelo favorecimento de modalidades com resultados em competições internacionais, que possuem outros patrocinadores e estrutura administrativa adequada ${ }^{16}$.

Ao analisar as ações provenientes da verba de repasse da Lei Agnelo/Piva no período entre 2005 e 2008, os autores verificaram que além de fortalecer o quadro de confederações dominantes e dominadas, a lei também fortalece a dependência financeira das confederações com relação ao COB (ALMEIDA; MARCHI JÚNIOR, 2012).

Silva et al (2015) optaram por analisar as formas de financiamento federal destinadas à Confederação Brasileira de Rugby (CBRu). Observou-se um crescimento nos recursos da CBRu de $2011^{17}$ em diante, sendo a LIE a principal fonte de financiamento.

E, por último, como único artigo que investigou as entidades de prática esportiva, Maroni, Mendes e Bastos (2010) analisaram a gestão e organização das equipes de voleibol que disputaram a Superliga 2007/2008. Os autores concluíram que a iniciativa privada desempenhou importante papel no desenvolvimento da modalidade no Brasil, sendo crescente a participação de entidades de prática esportiva criadas pelas empresas patrocinadoras.

\footnotetext{
${ }^{16}$ A estrutura administrativa adequada passa a ser elemento de vantagem entre as confederações, visto que cabe às confederações enviar projeto de solicitação financeira ao COB.

${ }^{17}$ Ano em que a modalidade rugby se tornou olímpico, levando a CBRu a receber repasses do COB a partir desta data.
} 
Apesar de poucos estudos pertencentes a essa categoria, vislumbramos algumas características: o favorecimento de modalidades que possuem expressivos resultados esportivos e patrocinadores privados, a centralidade do $\mathrm{COB}$ no apoio financeiro às confederações e o fortalecimento do cenário de confederações dominantes e dominadas.

\section{CONSIDERAÇÕES FINAIS}

Conseguimos compreender neste estudo as problemáticas sobre as quais a comunidade científica tem se dedicado a investigar. Nos chama a atenção o fato da primeira publicação sobre financiamento do esporte, a despeito do referido recorte temporal (1998-2018), ter sido divulgada apenas em 2009. A despeito disso, desde então, as publicações sobre a temática vêm crescendo. Este dado articulado ao quantitativo de 43 artigos publicados nos faz refutar o argumento de que há uma incipiência na produção sobre financiamento do esporte no país, embora tenhamos identificado determinadas lacunas presentes neste balanço.

Houve, no conjunto analisado, a priorização das análises da esfera federal: foram trinta e três (33) artigos, sendo quatro (04) sobre a esfera municipal, três (03) sobre o Distrito Federal, dois (02) sobre a esfera estadual e um (01) sobre o âmbito privado. Assim, verificamos uma incipiência de publicações em relação às esferas subnacionais e privadas.

Tendo por base as diferentes fontes de financiamento público do esporte foi possível identificar que a maioria dos artigos analisou a fonte orçamentária. No que se refere às fontes extraorçamentárias, não encontramos estudos sobre o patrocínio esportivo das empresas estatais ou as contribuições sobre salários e transferências de atletas profissionais. Em relação à fonte gastos tributários, encontramos apenas um estudo sobre a LIE.

A categoria que apresentou maior número de artigos publicados foi 'Políticas e programas esportivos específicos', e a predominância foi para a esfera federal. A concentração de recursos ${ }^{18}$ e a baixa execução orçamentária surgiram em diferentes políticas e programas esportivos analisados.

A categoria 'Gasto com a politica esportiva ou o orçamento esportivo' foi a segunda mais pesquisada, com uma concentração de artigos investigando a esfera federal e no período dos governos Lula e primeiro mandato de Dilma. Mesmo com os diferentes objetos analisados, verificamos características padrões do financiamento do esporte nesta categoria: ampliação e descontinuidade dos gastos, baixa execução orçamentária, modificação na priorização do gasto com esporte e priorização dos gastos com infraestrutura e megaeventos esportivos.

\footnotetext{
${ }^{18}$ A partir do favorecimento em diferentes programas e políticas pelos mesmos indivíduos.
} 
A terceira categoria, 'Megaeventos esportivos', concentrou as atenções para pesquisas sobre os Jogos Olímpicos Rio 2016. Verificamos uma necessidade de se averiguar o financiamento dos megaeventos esportivos no Brasil, principalmente com objetivos em investigar os legados esportivos. Compreendemos a dificuldade de acesso a determinadas informações e dados, bem como a limitação da mensuração dos legados dos megaeventos (PRONI, 2009), o que vem a justificar a baixa produtividade sobre a temática.

A última categoria pesquisada, 'Entidades de administração esportiva', com apenas quatro (04) artigos, apontou carências de produção nesta categoria. De forma similar, algumas pesquisas da categoria verificaram concentrações de recursos e favorecimento de determinadas modalidades/confederações. Considerando o número de confederações de esportes, o cenário incipiente de produção acadêmico-científica é um limite importante para a compreensão dessa dimensão do financiamento.

Percebemos que, de forma geral, os estudos sobre financiamento esportivo no Brasil vêm crescendo nos últimos anos. Porém, se olharmos as especificidades de cada categoria, enxergamos lacunas importantes, como no caso das pesquisas em âmbito estaduais e municipais, assim como dos megaeventos esportivos e das entidades de administração esportiva. Possivelmente, a preferência pelas pesquisas na esfera federal diz respeito a alguns fatores, como a transparência dos dados, a centralidade da fonte orçamentária e a continuidade das políticas públicas realizadas pelo ME.

Também verificamos uma concentração de pesquisas no período dos governos petistas, o que sinaliza uma resposta à ampliação de políticas e programas a partir de 2003 com a criação do ME e a partir de 2007 com a execução do primeiro megaevento. Assim, foi possível identificar que o foco de gasto da política esportiva em âmbito federal foi se remodelando ao longo do tempo.

Ademais, destacamos a importância do desenvolvimento de pesquisas quantitativoqualitativas que extrapolem análises meramente quantitativas e que consigam revelar o que tem sido priorizado nas políticas esportivas, apontando suas contradições, limites e possibilidades. Aspectos que abrem perspectivas para uma nova agenda de pesquisas sobre financiamento do esporte no país, incorporando, por isso, estudos com vistas à compreensão dos recursos de origem privada, dos reais gastos e dos legados dos megaeventos. Da mesma forma, esferas subnacionais também devem entrar na agenda de produções acadêmico-científicas. 


\section{REFERÊNCIAS}

ALMEIDA, Bárbara; MARCHI JÚNIOR, Wanderley. O financiamento dos programas federais de esporte e lazer no Brasil (2004 a 2008). Movimento, Porto Alegre, v. 16, n. 04, p. 73-92, out./dez. 2010.

ALMEIDA, Bárbara; MARCHI JÚNIOR, Wanderley. Comitê Olímpico Brasileiro e o financiamento das confederações brasileiras. Rev Bras Ciênc Esporte, 2011, 33:163-79. 2011.

ALMEIDA, Bárbara; MARCHI JÚNIOR, Wanderley. A relação Governo Federal e Comitê Olímpico Brasileiro com base na análise da Lei 10.264/2001 (Agnelo-Piva) no período de 2005 a 2008. Pensar a Prática, Goiânia, v. 15, n. 3, p. 551-820, jul./set. 2012.

AMARAL, Silvia; RIBEIRO, Olívia Cristina; SILVA, Dirceu. Produção científico-acadêmica em políticas públicas de esporte e lazer no brasil. Motrivivência, v. 26, n. 42, p. 27-40, junho/2014.

ATHAYDE, Pedro Fernando Avalone. O "lugar do social" na política de esporte do governo Lula. IN: MATIAS, Wagner; ATHAYDE, Pedro Fernando; MASCARENHAS, Fernando. Políticas de esporte nos anos Lula e Dilma. Brasília: Thesaurus, 2015.

ATHAYDE, Pedro Fernando Avalone; MASCARENHAS, Fernando; SALVADOR, Evilasio. Primeiras aproximações de uma análise do financiamento da política nacional de esporte lazer no governo Lula. Rev. Bras. Cien. Esporte, 37 (1). 2015.

ATHAYDE, Pedro Fernando Avalone; DALMAS, Leandro. Políticas de esporte do Distrito Federal: uma análise sobre a legislação, gestão e o financiamento entre os anos de 2008 a 2014. R. bras. Ci. e Mov 2018;26(2):113-128. 2018.

BARDIN, Laurence. Análise de conteúdo. São Paulo: Edições 70, 2011.

BRACHT, V. et. al. Educação Física Escolar como tema da produção do conhecimento nos periódicos da área no Brasil (1980-2010): parte I. Revista Movimento, v. 17, n. 2, p. 11-34, 2011.

CAMARGO, Philipe; MEZZADRI, Fernando. A organização e configuração do esporte universitário no Brasil (1940-1980). Motrivivência, Florianópolis/SC, v. 30, n. 53., p. 52-68, maio/2018.

CARNEIRO, Fernando Henrique; MASCARENHAS, Fernando. O direito ao esporte: análise do planejamento e execução de políticas públicas no Distrito Federal no período 2008-2011. Licere, Belo Horizonte, v.17, n.2, jun/2014.

CARNEIRO, Fernando Henrique; MASCARENHAS, Fernando. O financiamento esportivo brasileiro: proposta de metodologia crítica de análise. E-legis, Brasília, Número Especial - Pesquisas e Políticas sobre Esporte, nov. 2018.

CARNEIRO, Fernando Henrique et al. Os centos olímpicos do Distrito Federal: um caso de desresponsabilização do Estado e descentralização das políticas de esporte e lazer em direção ao "terceiro setor". Licere, Belo Horizonte, v.21, n.2, jun/2018.

CASTRO, Suélen; SOUZA, Doralice. Os jogos olímpicos e paraolímpicos Rio 2016: propostas para o esporte educacional, de participação e de rendimento. Rev Bras Educ Fís Esporte, (São Paulo) 2015 JulSet; 29(3):507-18. 2015.

CASTRO, Suélen; POFFO, Bianca; SOUZA, Doralice. O financiamento do esporte de alto rendimento no Brasil: uma análise do programa "Brasil no Esporte de Alto Rendimento" (2004-2011). R. bras. Ci. e Mov 2016;24(3):146-157. 2016. 
CASTRO, Suélen; SCARPIN, Jorge; SOUZA, Doralice. Financiamento público e esporte educacional: uma análise do processo orçamentário do programa "Segundo Tempo" (2004-2011). Motrivivência,

Florianópolis/SC, v. 29, n. 52, p. 136-156, setembro/2017.

CASTRO, Suélen; STAREPRAVO, Fernando; SOUZA, Doralice. Programa "esporte e lazer da cidade": uma análise da composição orçamentária (2004-2011). Movimento, Porto Alegre, v. 24, n. 2, p. 383-398, abr./jun. de 2018.

COAKLEY, Jay; SOUZA, Doralice. Legados de megaeventos esportivos: considerações a partir de uma perspectiva crítica. Rev Bras Educ Fís Esporte, (São Paulo) 2015 Out-Dez; 29(4):675-86. 2015.

CORRÊA, Amanda et al. Financiamento do esporte olímpico de verão brasileiro: mapeamento inicial do programa "bolsa-atleta" (2005-2011). Pensar a Prática, Goiânia, v. 17, n. 4, out./dez. 2014.

DIAS, Yuri Rafael et al. O panorama do judô no programa "bolsa-atleta": uma análise entre os anos de 2011 e 2013. Motrivivência v. 28, n. 49, p. 82-98, dezembro/2016a.

DIAS, Yuri Rafael et al. O judô no programa governamental bolsa-atleta: a distribuição espacial dos bolsistas (2011-2013). Pensar a Prática, Goiânia, v. 19, n. 1, jan./mar. $2016 b$.

FIGUERÔA, K.; MEZZADRI, F.; SILVA, M. Rio 2016 e os legados do esporte de lazer. Licere, Belo Horizonte, v.17, n.3, set/2014.

FIGUERÔA, Katiuscia; MEZZADRI, Fernando; SILVA, Marcelo. Rio 2016: possibilidades e desafio para o esporte brasileiro. Motrivivência Ano XXV, No 41, P. 140-154 Dez./2013.

FIGUERÔA, Katiuscia et al. Planejamento, ações e financiamento para o esporte em tempos de megaeventos. Motrivivência v. 26, n. 42, p. 55-71, junho/2014.

FURTADO, Sabrina et al. O financiamento do esporte em Santa Catarina: o caso do Fundesporte nos anos de 2011 e 2012. Motrivivência v. 28, n. 47, p. 145-159, maio/2016.

GRASSO, Rita. ISAYAMA, Hélder. Financiamento e políticas públicas de esporte e lazer: uma análise da gestão no município de Santarém/PA (2005-2010). R. bras. Ci. e Mov. 2017; 25 (1): 151-167. 2017.

MARONI, Fernando; MENDES, Dilson; BASTOS, Flávia. Gestão do voleibol no Brasil: o caso das equipes participantes da Superliga 2007-2008. Rev. bras. Educ. Fís. Esporte, São Paulo, v.24, n.2, p.239-48, abr./jun. 2010.

MASCARENHAS, Fernando. O orçamento do esporte: aspectos da atuação estatal de FHC a Dilma. Rev. Bras. Educ. Fís. Esporte, São Paulo, v. 30, n. 4, p. 963-80, out./dez. 2016.

MATIAS, Wagner. A política esportiva do governo Lula: o programa Segundo Tempo. Licere, Belo Horizonte, v.16, n.1, mar/2013.

MATIAS, Wagner; MASCARENHAS, Fernando. As influências dos megaeventos esportivos na agenda e políticas esportivas: planejamento institucional, ordenamento jurídico e financiamento. Pensar a Prática, Goiânia, v. 20, n. 1, jan./mar. 2017.

MATIAS, Wagner et al. A Lei de Incentivo Fiscal e o (não) direito ao esporte. Movimento, Porto Alegre, v. 21, n. 1, p. 95-110, jan./mar. de 2015.

MEZZADRI, Fernando Marinho; SILVA, Marcelo Moraes e; FIGUERÔA, Katiuscia Mello. Desenvolvimento de um método para as pesquisas em políticas públicas de esporte no brasil: uma abordagem de pesquisa mista. Motrivivência, v. 27, n. 44, p. 49-63, maio/2015. 
OLIVEIRA, Ana Amélia; SUASSUNA, Dulce; TROMPIERI FILHO, Nicolino. Do direito ao lazer: o princípio acesso no programa esporte a comunidade (Fortaleza-CE). Licere, Belo Horizonte, v. 16, n.4, $\operatorname{dez} / 2013$.

ORDONHES, Mayara; LUZ, Wallinson; CAVICHIOLLI, Fernando. Possíveis relações entre investimentos públicos e obtenção de resultados: o caso da natação brasileira. Motrivivência, v. 28, n. 47, p. 82-95, maio/2016.

PEREIRA, P. Discussões conceituais sobre política social como política pública e direito de cidadania. IN: Política Social no Capitalismo: Tendências Contemporâneas. 2 ed. São Paulo: Cortez, 2009.

PINTOS, Ana Elenara; ATHAYDE, Pedro Fernando; GODOFLITE, Marilise. Municipalização do esporte e do lazer. Licere, Belo Horizonte, v.20, n.3, set/2017.

PRONI, Marcelo. Observações sobre os impactos esperados dos Jogos Olímpicos de 2016. Motrivivência Ano XXI, No 32/33, P. 49-70 Jun-Dez./2009.

QUINAUD, Ricardo; ALMEIDA, Bárbara. Financiamento público no esporte: os repasses do estado de Santa Catarino para projetos na mesorregião grande Florianópolis (2007-2014). Pensar a Prática, Goiânia, v. 21, n. 2, abr./jun. 2018.

RIBEIRO, Mariângela et al. A agenda do futebol no governo Lula: ações rumo à Copa do Mundo FIFA 2014. Motrivivência, v. 29, n. 50, p. 90-103, maio/2017.

SALVADOR, Evilasio. Fundo Público e o financiamento das Políticas Sociais no Brasil. Serv. Soc. Rev., Londrina, v. 14, n. 2, p. 04-22, jan./jun, 2012.

SAMPAIO, R. F.; MANCINI, M. C. Estudos de revisão sistemática: um guia para síntese criteriosa da evidência científica. Revista Brasileira de Fisioterapia, São Carlos, v. 11, n.1, p. 83-89, jan./fev. 2007.

SANTOS, Edmilson; STAREPRAVO, Fernando; CANAN, Felipe. Evolução das despesas da função desporto e lazer (FDL) dos municípios do estado do Piauí de 2003 a 2011. Motrivivência, Florianópolis/SC, v. 30, n. 55 , p. 20-33, setembro/2018.

SANTOS, Edmilson; STAREPRAVO, Fernando. Análise da capacidade fiscal per capita na descentralização do programa Segundo Tempo/ME junto aos municípios. Movimento, Porto Alegre, v. 24, n. 4, p. 10971110, out./dez. de 2018a.

SANTOS, Edmilson; STAREPRAVO, Fernando. Estrutura político-adminsitrativa dos governos municipais do Piauí e investimento no esporte e no lazer. Licere, Belo Horizonte, v.21, n.4, dez/2018b.

SILVA, Marcelo Moraes e et al. O financiamento público do rugby brasileiro: a relação Governo Federal e Confederação Brasileira de Rugby (CBRu). Rev. Educ. Fís/UEM,v. 26, n. 2, p. 213-222, 2. trim. 2015.

SILVA, Dirceu; BORGES, Carlos; AMARAL, Silvia. Gestão das políticas públicas do Ministério do Esporte do Brasil. Rev Bras Educ Fís Esporte, (São Paulo) 2015 Jan-Mar; 29(1):65-79. 2015.

SOARES, Manoel; BEHMOIRAS, Daniel; SAMPAIO, Juarez. A cidadania ferida no país da copa: as obras públicas para os megaeventos sob o sorriso do lagarto. Motrivivência Ano XXV, No 41, P. 128-139

Dez./2013.

SOARES, José. O programa Esporte e Lazer da Cidade nos planos plurianuais do governo federal: o "estresse esportivo" do PELC. Licere, Belo Horizonte, v.20, n.3, set/2017. 
STAREPRAVO, Fernando Augusto; SOUZA, Juliano de Souza; MARCHI JÚNIOR, Wanderley. Políticas Públicas de Esporte e Lazer no Brasil: Uma Proposta Teórico-Metodológica de Análise. Movimento, Porto Alegre, v. 17, n. 03, p. 233-251, jul/set de 2011.

STAREPRAVO, Fernando et al. Esporte universitário brasileiro: uma leitura a partir de suas relações com o Estado. Rev. Bras. Cienc. Esporte, Campinas, v. 31, n. 3, p. 131-148, maio 2010.

TEIXEIRA, Marcelo et al. O programa bolsa atleta no contexto esportivo nacional. Motrivivência, Florianópolis/SC, v. 29, n. esp., p. 92-109, dezembro/2017.

TEIXEIRA, Marcelo; MATIAS, Wagner; MASCARENHAS, Fernando. O esporte olímpico no Brasil: recursos financeiros disponibilizados para Olimpíadas Londres 2012. Rev Bras Ciênc Esporte. 2017;39(3):284-290. 2017.

TEIXEIRA, Marcelo et al. Esporte, fundo público e pequena política: os reveses de um orçamento (r)emendado. Movimento. V. 24, n. 2, p. 593-606, abr./jun. de 2018.

\section{NOTAS DE AUTOR}

\section{AGRADECIMENTOS}

Não se aplica.

\section{CONTRIBUIÇÃO DE AUTORIA}

Não se aplica.

\section{FINANCIAMENTO}

Este estudo foi realizado com o apoio da Coordenação de Aperfeiçoamento de Pessoal de Nível Superior (CAPES) - Código de Financiamento 001.

\section{CONSENTIMENTO DE USO DE IMAGEM}

Não se aplica.

\section{APROVAÇÃO DE COMITÊ DE ÉTICA EM PESQUISA}

Não se aplica.

\section{CONFLITO DE INTERESSES}

Não se aplica.

\section{LICENÇA DE USO}

Os autores cedem à Motrivivência - ISSN 2175-8042 os direitos exclusivos de primeira publicação, com o trabalho simultaneamente licenciado sob a Licença Creative Commons Attribution Non-Comercial ShareAlike (CC BY-NC SA) 4.0 International. Esta licença permite que terceiros remixem, adaptem e criem a partir do trabalho publicado, desde que para fins não comerciais, atribuindo o devido crédito de autoria e publicação inicial neste periódico desde que adotem a mesma licença, compartilhar igual. Os autores têm autorização para assumir contratos adicionais separadamente, para distribuição não exclusiva da versão do trabalho publicada neste periódico (ex.: publicar em repositório institucional, em site pessoal, publicar uma tradução, ou como capítulo de livro), com reconhecimento de autoria e publicação inicial neste periódico, desde que para fins não comerciais e compartilhar com a mesma licença. 


\section{PUBLISHER}

Universidade Federal de Santa Catarina. Programa de Pós-Graduação em Educação Física. LaboMídia - Laboratório e Observatório da Mídia Esportiva. Publicado no Portal de Periódicos UFSC. As ideias expressadas neste artigo são de responsabilidade de seus autores, não representando, necessariamente, a opinião dos editores ou da universidade.

\section{EDITORES}

Mauricio Roberto da Silva, Giovani De Lorenzi Pires, Rogério Santos Pereira

\section{HISTÓRICO}

Recebido em: 29 de abril 2019.

Aprovado em: 08 de julho 2019. 